\title{
Dissociative electron attachment reactions of transition metal carbonyls and their apparent influence on the thermalization of electrons by $\mathrm{CO}_{2}{ }^{\text {a) }}$
}

\author{
Patricia M. George and J. L. Beauchamp \\ Arthur Amos Noyes Laboratory of Chemical Physics, California Institute of Technology, Pasadena, \\ California 91125 \\ (Received 20 March 1981; accepted 30 March 1981)
}

\begin{abstract}
Dissociative electron attachment rates are measured for the transition metal carbonyls $\mathrm{V}(\mathrm{CO})_{6}, \mathrm{Cr}(\mathrm{CO})_{6}$, $\mathrm{Fe}(\mathrm{CO})_{9}, \mathrm{Ni}(\mathrm{CO})_{4}, \mathrm{Mo}(\mathrm{CO})_{6}$, and $\mathrm{W}(\mathrm{CO})_{6}$. Rates are measured as a function of the pressure of $\mathrm{CO}_{2}$ added to relax epithermal electrons. Derived thermal rate constants for the formation of $\mathrm{M}(\mathrm{CO})_{n-1}^{-}$from $\mathrm{M}(\mathrm{CO})_{n}$ are $0.6,3.0,2.0,2.0,1.3$, and $1.2 \times 10^{-7} \mathrm{~cm}^{3}$ molecule ${ }^{-1} \mathrm{~s}^{-1}$, respectively. The differences in these rate constants may be attributed to the different stabilities of the molecular anion with regard to dissociation versus autodetachment. The measured rate of thermalization of electrons by $\mathrm{CO}_{2}$ varies with the metal carbonyl used and depends on the variation of the dissociative electron capture cross section with electron energy. Each system is thus tightly coupled in that the electron energy distribution is determined not only by collisional processes involving $\mathrm{CO}_{2}$ but varies as well with the energy dependent depletion of the distribution by reactant species.
\end{abstract}

\section{INTRODUCTION}

Electron capture rates for many molecules are extremely high. For example, organohalogen compounds, which are the main electron capture detection agents, have rate coefficients often reaching $\sim 2 \times 10^{-7} \mathrm{~cm}^{3}$ molecule ${ }^{-1}$ $\mathrm{s}^{-1}$. At 1 Torr this gives a reaction rate of $10^{10} \mathrm{~s}^{-1}$. Consequently, direct monitoring of electron capture processes at 1 Torr requires experiments with picosecond time resolution and indirect methods are usually employed. Lower pressures increase the time scale of the experiment, making it possible to use a variety of techniques to directly monitor electron capture process es. For example, at $10^{-8}$ Torr attachment is complete in $\sim 10 \mathrm{~ms}$ and direct investigations of such processes can be accomplished in this pressure range with instruments having millisecond time resolution. A particularly useful technique in this time domain is that of ion cyclotron resonance spectroscopy. The ICR cell serves as an electromagnetic bottle in which electrons can be efficiently trapped and cooled. Ion detection times are $\sim$ 1-2 $\mathrm{ms}$ in order to have reasonable mass resolution. Thus, electron attachment experiments with molecular densities in the $10^{9} \mathrm{~cm}^{-3}$ range are extremely well suited to study by ICR techniques. The long time scale and low pressures associated with this experimental methodology have facilitated examination of radiative electron attachment processes leading to formation of stable molecular radical anions. ${ }^{1,2}$ In addition, it has been observed that dissociative electron attachment occurs at low pressures with the same facility as high pressures because no stabilization is required. ${ }^{2}$ With the exception of the limited results reported for $\mathrm{CCl}_{4},{ }^{2}$ no systematic study has been undertaken to investigate dissociative electron attachment processes at such low pressures.

A general mechanism describing dissociative electron attachment is illustrated below:

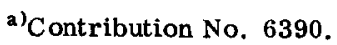

$\left(e^{-}\right) * \frac{k_{1}[\mathrm{M}]}{\left.e^{-}\right)^{*}} e_{\mathrm{th}}^{-}+\mathrm{A} \underset{k_{2}[\mathrm{~A}]}{\stackrel{k_{f}}{k_{i}}}\left[\mathrm{~A}^{-}\right]^{*} \stackrel{k_{d}}{-} B^{-}+\mathrm{C}$

Electrons, with a distribution of energies, are thermalized either by the reacting species $A$ or a buffer gas $M$. Subsequent attachment by molecule $A$ leads to the formation of $\left[\mathrm{A}^{-}\right]^{*}$, which can dissociate to form a neutral and a negative ion or autodetach the electron.

The process of electron thermalization is, surprisingly, still not well characterized, even though many experiments are carried out in an excess of a buffer gas which is assumed to thermalize electrons. Some attempts, however, have been made to experimentally determine thermalization times as a function of electron energy. ${ }^{3,4}$ Data obtained in swarm experiments by Christophorou and co-workers ${ }^{3}$ are illustrated in Fig. 1. The thermalizing gas in this case is $\mathrm{CO}_{2}$, and the rate constant for electron thermalization is plotted versus the mean electron energy. The relaxation rate decreases with increasing energy, reaching a constant value of $\sim 3.8 \times 10^{-10} \mathrm{~cm}^{3}$ molecule $\mathrm{e}^{-1} \mathrm{~s}^{-1}$ at an average electron energy of $\sim 0.8 \mathrm{eV}$. Warman and Sauer ${ }^{4}$ have also investigated electron thermalization by $\mathrm{CO}_{2}$, studying the process under conditions such that the time scale of thermalization was comparable with that of attachment of electrons to $\mathrm{CCl}_{4}$. This necessarily resulted from the use of dissociative attachment of electrons by $\mathrm{CCl}_{4}$ to monitor the $\mathrm{CO}_{2}$ relaxation rate. They derive a thermalization rate constant of $5.8 \times 10^{-9}$ $\mathrm{cm}^{3}$ molecule $\mathrm{e}^{-1} \mathrm{~s}^{-1}$. In their experiments it appears that the electrons had a wide range of initial energies.

Compared to most small molecules, $\mathrm{CO}_{2}$ is uniquely efficient as a bath gas for electron thermalization. This is due to the fact that $\mathrm{CO}_{2}$ forms temporary negative ions at low energies, with electron capture occurring into discrete but short-lived autodetaching states of $\mathrm{CO}_{2}^{-}$. Autodetachment leaves vibrationally excited $\mathrm{CO}_{2}$ and an electron with lower energy. ${ }^{5}$ 


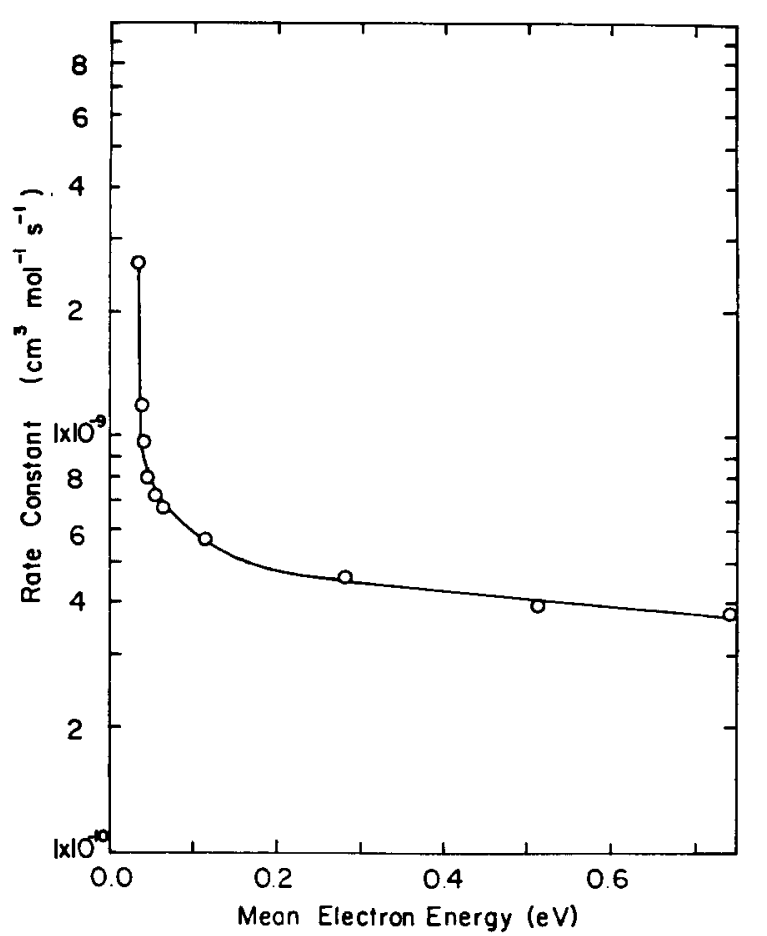

FIG. 1. Thermalization rate constant as a function of mean electron energy for electrons in $\mathrm{CO}_{2}$. Data are taken from Ref. 3.

attachment to transition metal carbonyls. Dissociative attachment rates are measured as a function of $\mathrm{CO}_{2}$ pressure. The carbonyls studied include $\mathrm{V}(\mathrm{CO})_{6}$, $\mathrm{Cr}(\mathrm{CO})_{6}, \mathrm{Fe}(\mathrm{CO})_{5}, \mathrm{Ni}(\mathrm{CO})_{4}, \mathrm{Mo}(\mathrm{CO})_{6}$, and $\mathrm{W}(\mathrm{CO})_{6}$. Negative ion formation from these species has been investigated previously in varying detail. ${ }^{6-11}$ Parent negative ions are not observed except in $\mathrm{V}(\mathrm{CO})_{6} \cdot{ }^{9}$ In this particular case the extra electron can occupy a bonding orbital. The dissociative products of $\mathrm{Fe}(\mathrm{CO})_{5}$ and $\mathrm{Ni}(\mathrm{CO})_{4}$ have been examined at higher resolution in gas phase collision experiments. ${ }^{10}$ Onset for formation of both $\mathrm{Fe}(\mathrm{CO})_{4}^{-}$and $\mathrm{Ni}(\mathrm{CO})_{3}^{-}$occurs at $0 \mathrm{eV}$ but $\mathrm{Ni}(\mathrm{CO})_{3}^{-}$ peaks at thermal energies while $\mathrm{Fe}(\mathrm{CO})_{4}^{-}$continues to increase with electron energy until it reaches a maximum at $\sim 0.5 \mathrm{eV}$. The energetics associated with formation of $\mathrm{Fe}(\mathrm{CO})_{4}^{-}$from $\mathrm{Fe}(\mathrm{CO})_{5}$ are illustrated in Fig.

2. It can be seen in this case that the process

$$
\mathrm{Fe}(\mathrm{CO})_{5}+e-\mathrm{Fe}(\mathrm{CO})_{4}^{-}+\mathrm{CO}
$$

is approximately thermoneutral, with the electron af-

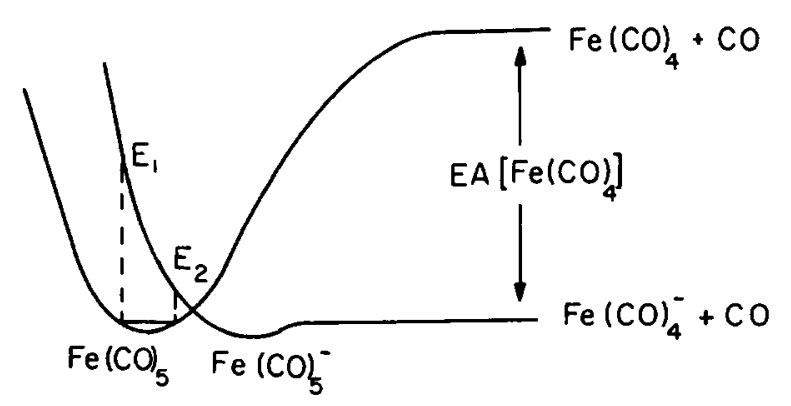

FIG. 2. Energetics associated with formation of $\mathrm{Fe}(\mathrm{CO})_{4}^{-}$from $\mathrm{Fe}(\mathrm{CO})_{5}$. Dissociative attachment occurs with electron energies between $E_{1}$ and $E_{2}$.

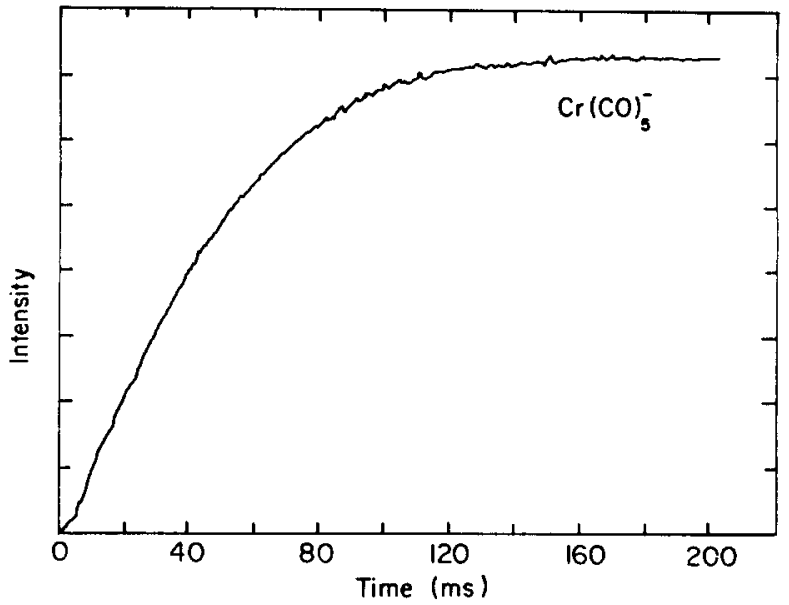

FIG. 3. Typical trapped ion data for dissociative electron attachment to $\mathrm{Cr}(\mathrm{CO})_{6}$. The trap is filled with electrons by a 3 $\mathrm{ms}$ electron beam pulse. $\mathrm{Cr}(\mathrm{CO})_{6}$ pressure is $2.7 \times 10^{-8}$ Torr.

finity of $\mathrm{Fe}(\mathrm{CO})_{4}$ obtained by photoelectron spectroscopy $^{11}$ being approximately equal to $\mathrm{D}\left[\mathrm{Fe}(\mathrm{CO})_{4}-\mathrm{CO}\right]$.

\section{EXPERIMENTAL}

The ICR spectrometer used in these studies utilizes a 15 in. magnet with a maximum field of $23.4 \mathrm{kG}$, flat three-section ICR cell, and standard marginal oscillator detector. Trapped ion ICR techniques have been described elsewhere in detail. ${ }^{12}$ Electrons are supplied to the source region of the ICR cell by an initial $3 \mathrm{~ms}, 70 \mathrm{eV}$ electron beam pulse. The scattered electrons in this region exhibit kinetic energies up to $\sim 0.9 V_{t}$ in the direction of the magnetic field, where $V_{t}$ is the applied trapping voltage. These electrons are constrained to remain on an equipotential of the applied field. They may then react with neutral species to form negative ions which can be trapped in the cell by applied electrostatic fields. Detection is effected after a suitable delay by drifting the ions from the source to the analyzer region where they are observed using a marginal os cillator.

Absolute pressure measurements were made using a Schulz-Phelps ion gauge, calibrated against an MKS Baratron, model 90H1-E capacitance manometer. Overall accuracy in pressure measurements is approximately $\pm 20 \%$, which represents the major source of er ror in reaction rate constants. All experiments were conducted at ambient temperature $(298 \mathrm{~K})$.

Chemicals were obtained commercially and used without further purification. Noncondensible impurities were removed by several freeze-pump-thaw cycles at liquid nitrogen temperatures. Metal carbonyl vapor pressures ( $>10^{-2}$ Torr) were found to be adequate for all present experiments and impurities were negligible as determined by mass spectrometry.

\section{RESULTS}

Dissociative electron attachment processes were observed for all the transition metal carbonyls studied. Typical trapped ion data for formation of $\mathrm{Cr}(\mathrm{CO})_{5}^{-}$are shown in Fig. 3. Similar results were obtained for 
$\mathrm{Fe}(\mathrm{CO})_{4}^{-}, \mathrm{Mo}(\mathrm{CO})_{5}^{-}, \mathrm{W}(\mathrm{CO})_{5}^{-}, \mathrm{V}(\mathrm{CO})_{5}^{-}$, and $\mathrm{Ni}(\mathrm{CO})_{3}^{-}$. Electron attachment rate constants were measured in the same way as previously described for $\mathrm{SF}_{\mathrm{B}}{ }^{1}$ and fluorinated hydrocarbons. ${ }^{2}$ Shortly after termination of the electron beam pulse the curve in Fig. 1 can be represented by

$$
\left[\mathrm{B}^{-}\right]=\left[\mathrm{B}^{-}\right]_{\infty \infty}\left\{1-\exp \left(-k_{\text {app }}[\mathrm{A}] t\right)\right\},
$$

where $\left[\mathrm{B}^{-}\right]_{\infty}$ is the anion abundance at long times and $k_{200}$ is the apparent bimolecular rate constant. The initial period of slower dissociative electron attachment is followed by rapid $M(C O)_{n}^{-}$formation with limiting slope $k_{\mathrm{app}}$ (Fig. 4). Since the rate limiting step at low pressures is relaxation of the electron energy distribution, ${ }^{2} k_{2 p p}$ is found to decrease with increasing trapping voltage. Figure 5 illustrates the variation in apparent attachment rates for $\mathrm{Cr}(\mathrm{CO})_{6}$ and $\mathrm{Fe}(\mathrm{CO})_{5}$. As noted above, trapped electrons have energies up to $0.9 \mathrm{~V}$ and the average electron energy will increase with increasing trapping voltage. In the case of $\mathrm{Fe}(\mathrm{CO})_{5}$, the variation in electron capture rate with the maximum electron energy parallels the formation of $\mathrm{Fe}(\mathrm{CO})_{4}^{-}$by electron impact reported by Compton and St ockdale [Fig. 5(b)]. ${ }^{10}$ A trapping voltage of $-1.5 \mathrm{eV}$ was chosen for all further experiments reported herein, corresponding to electron energies in the range $0-1.3 \mathrm{eV}$.

The attachment rates vary linearly with pressure of metal carbonyl up to $10^{-7}$ Torr (Fig. 6). The slope of Fig. 6 directly yields the apparent electron attachment rate constant and shows that it is independent of the pressure of the metal carbonyl. The apparent attachment rate does, however, vary with the pressure of added $\mathrm{CO}_{2}$ buffer gas. To measure high pressure attachment rates, increasing pressures of $\mathrm{CO}_{2}$ were added to $3 \times 10^{-8}$ Torr of the metal carbonyl. These re-

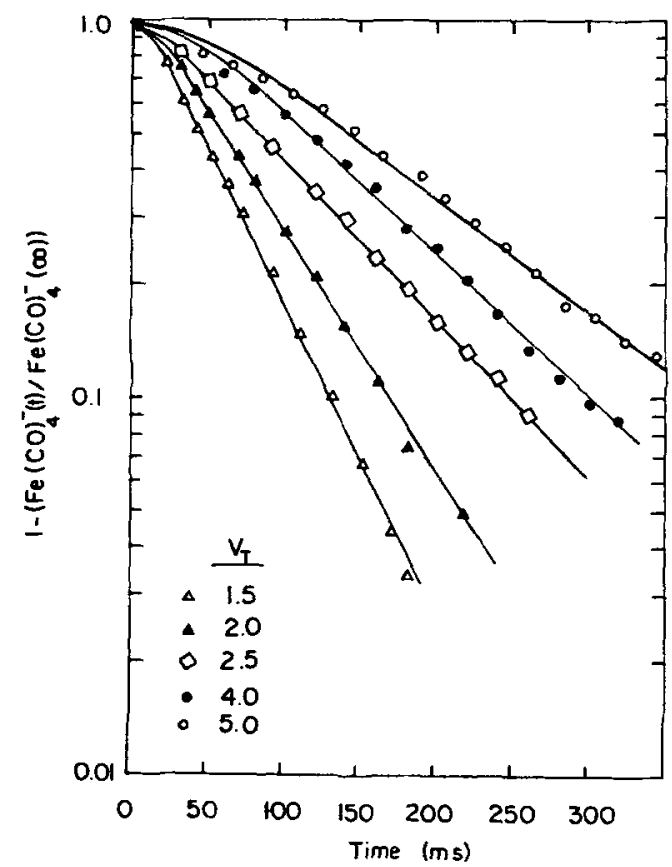

FIG. 4. Effect of trapping voltage on dissociative electron attachment to $\mathrm{Fe}(\mathrm{CO})_{5}$. [ $\mathrm{Fe}\left(\mathrm{CO}_{4}^{-}\right]_{\infty}$ is the ion abundance of $\mathrm{Fe}(\mathrm{CO})_{4}^{-}$when all the electrons have been attached.

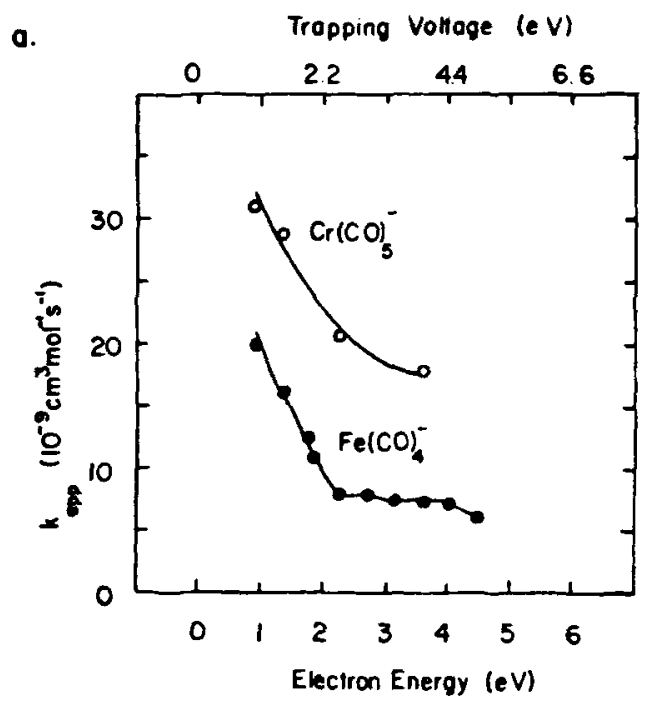

b.

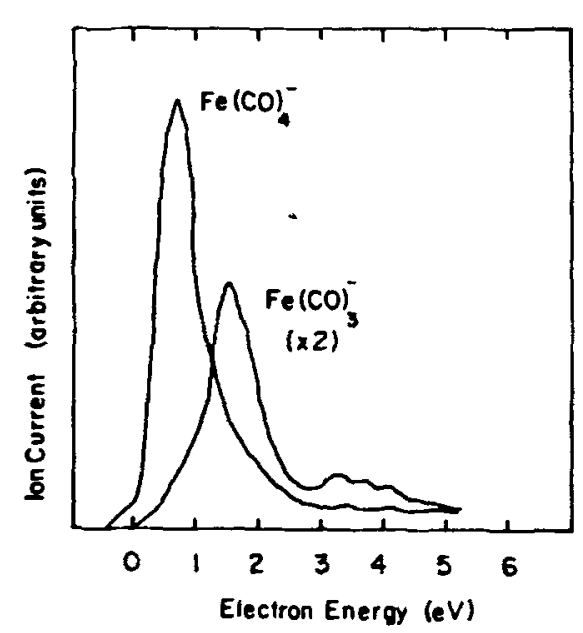

FIG. 5. (a) The effect of trapping voltage on the low pressure dissociative attachment rate constant $k_{\text {apv }}$ for $\mathrm{Cr}(\mathrm{CO})_{5}^{-}$and $\mathrm{Fe}(\mathrm{CO})_{4}^{-}$. Quoted electron energies (lower scale) represent the maximum electron energy, which is equal to $0.9 \mathrm{~V}$. (b) Yield of $\mathrm{Fe}(\mathrm{CO})_{4}^{-}$and $\mathrm{Fe}(\mathrm{CO})_{3}^{-}$as a function of electron energy using a low energy electron beam. Data are from Ref. 10.

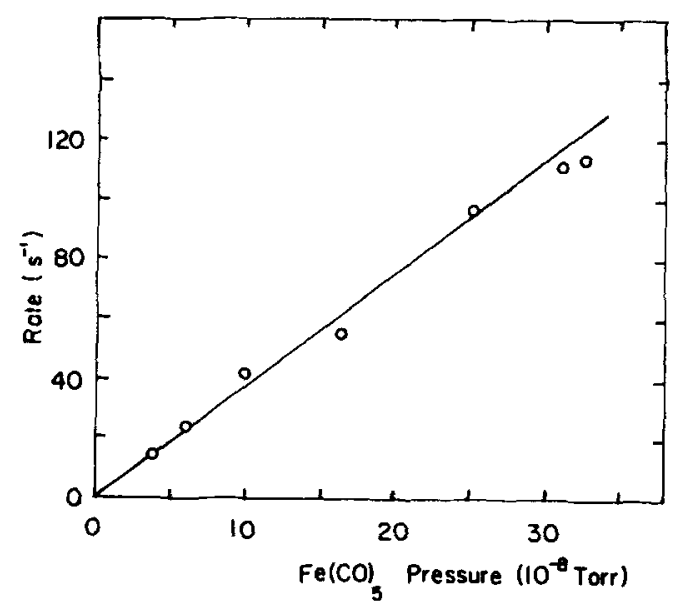

FIG. 6. Dissociative attachment rates as a function of $\mathrm{Fe}(\mathrm{CO})_{5}$ pressure with no $\mathrm{CO}_{2}$ present. 


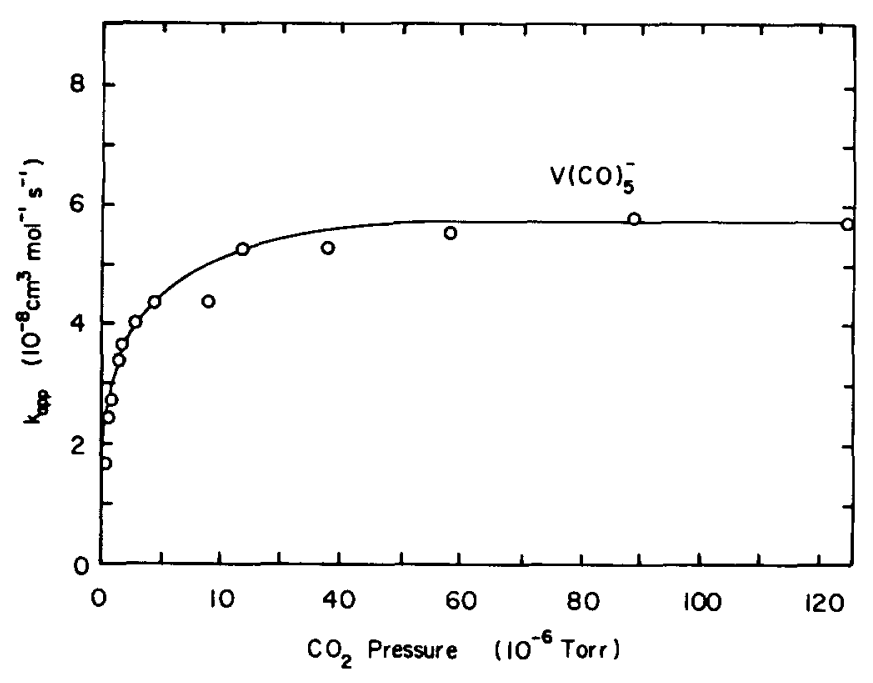

FIG. 7. Dissociative electron attachment rate constants as a function of $\mathrm{CO}_{2}$ pressure for $\mathrm{V}(\mathrm{CO})_{6}$.

sults are shown for all of the metal carbonyls in Figs. 7-12. Attachment rates are proportional to $\mathrm{CO}_{2}$ pressure until the high pressure limit is reached. From the slope of the linear portion of each curve a rate constant for electron thermalization by $\mathrm{CO}_{2}$ can be calculated. These values are given in Table I along with the high pressure limits for a relaxed thermal electron distribution.

\section{DISCUSSION}

With the exception of $\mathrm{V}(\mathrm{CO})_{6}$, the high pressure dissociative attachment rate constants are all in the same range, from $1 \times 10^{-7}$ to $3 \times 10^{-7} \mathrm{~cm}^{3}$ molecule $\mathrm{cs}^{-1}$. This is in agreement with the observations of Compton and Stockdale ${ }^{10}$ that ion currents obtained for $\mathrm{Fe}(\mathrm{CO})_{4}^{-}$, $\mathrm{Fe}(\mathrm{CO})_{3}^{-}$, and $\mathrm{Ni}(\mathrm{CO})_{3}^{-}$were comparable to $\mathrm{SF}_{\mathrm{B}}^{-}$currents under equivalent conditions. The rate constant for $S_{F}^{-}$ is also in the above range. ${ }^{13}$

Several factors distinguish $\mathrm{V}(\mathrm{CO})_{6}$ from the remaining carbonyls. The molecular anion $\mathrm{V}(\mathrm{CO})_{B}^{-}$is known to

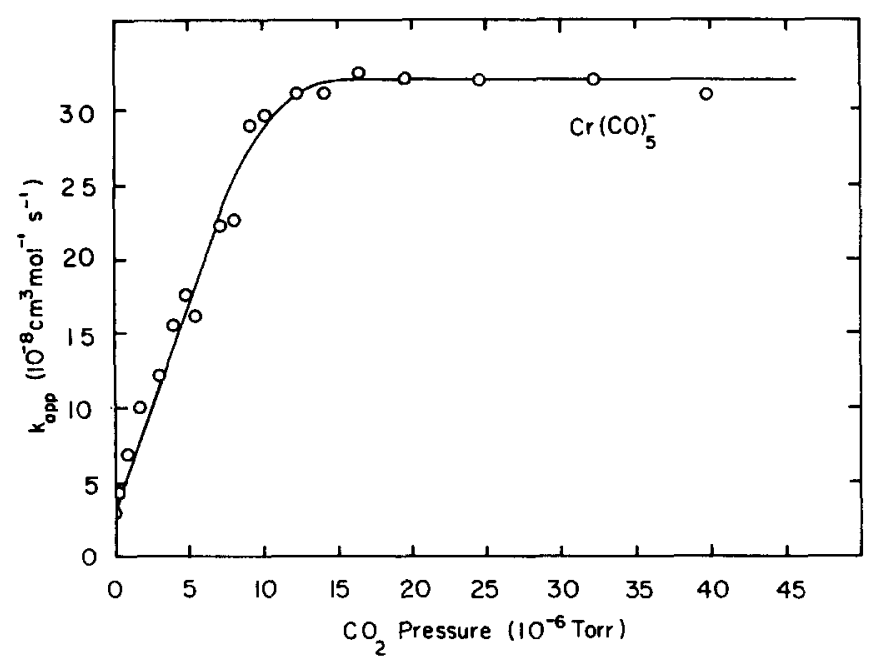

FIG. 8. Dissociative electron attachment rate constants as a function of $\mathrm{CO}_{2}$ pressure for $\mathrm{Cr}(\mathrm{CO})_{6}$.

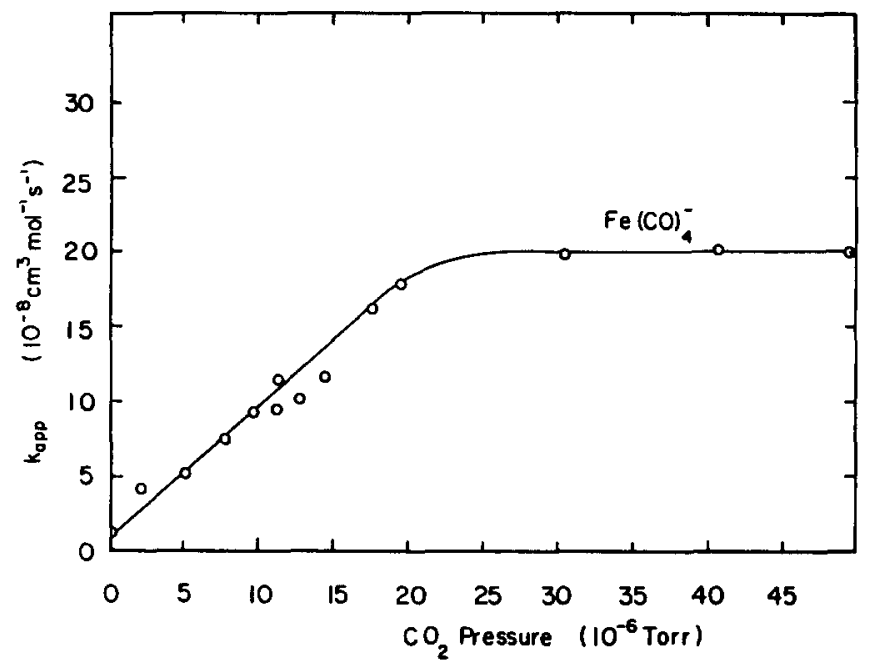

FIG. 9. Dissociative electron attachment rate constants as a function of $\mathrm{CO}_{2}$ pressure for $\mathrm{Fe}(\mathrm{CO})_{5}$.

be a stable species, ${ }^{8}$ formed by adding the extra electron to a bonding $t_{2 g}$ orbital to give a closed shell species. Both the anion and the neutral, which exhibit little if any Jahn-Teller distortion, are expected to have very similar octahedral structures. The remaining metal hexacarbonyls $\left[\mathrm{M}(\mathrm{CO})_{6}, \mathrm{M}=\mathrm{Cr}, \mathrm{Mo}, \mathrm{W}\right]$ capture an electron into an antibonding $e_{g}$ orbital. The resulting state may actually be repulsive with respect to loss of a $\mathrm{CO}$, or may be distorted sufficiently to inhibit electron autodetachment. Similar arguments can be applied to $\mathrm{Fe}(\mathrm{CO})_{5}$ and $\mathrm{Ni}(\mathrm{CO})_{4}$. Although we cannot provide definite proof, we suggest that the lower dissociative electron capture rate measured for $\mathrm{V}(\mathrm{CO})_{6}$ reflects the ability of autodetachment to compete with loss of CO.

The results in Table I show that $\mathrm{CO}_{2}$ moderates the electron energy with an apparent range of rate constants varying from $1 \times 10^{-11}$ to $3.2 \times 10^{-8} \mathrm{~cm}^{3}$ molecule $\mathrm{e}^{-1} \mathrm{~s}^{-1}$. The apparent rate of thermalizing electrons clearly depends on the species used to monitor the relaxation

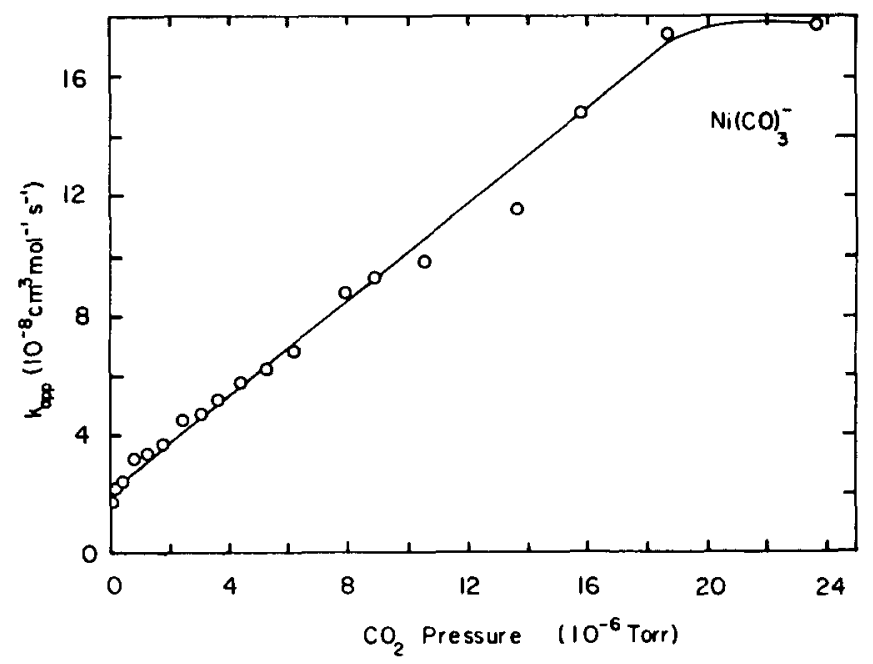

FIG. 10. Dissociative electron attachment rate constants as a function of $\mathrm{CO}_{2}$ pressure for $\mathrm{Ni}(\mathrm{CO})_{4}$. 
TABLE I. Rate constants for electron attachment and thermalization. ${ }^{\mathrm{a}}$

\begin{tabular}{llll}
\hline \hline Ion & $k_{\text {app }}{ }^{\mathrm{b}}$ & $k_{m}{ }^{\mathrm{c}}$ & $k_{\mathrm{CO}_{2}{ }^{\mathrm{d}}}$ \\
\hline $\mathrm{V}(\mathrm{CO})_{5}^{-}$ & $5.7 \times 10^{-8}$ & $1.6 \times 10^{-8}$ & $2.0 \times 10^{-10}$ \\
$\mathrm{~V}(\mathrm{CO})_{4}^{-}$ & $4.0 \times 10^{-8}$ & $2.2 \times 10^{-8}$ & $5.7 \times 10^{-10}$ \\
$\mathrm{Cr}(\mathrm{CO})_{5}^{-}$ & $3.2 \times 10^{-7}$ & $2.8 \times 10^{-8}$ & $9.1 \times 10^{-10}$ \\
$\mathrm{Fe}(\mathrm{CO})_{4}^{-}$ & $2.0 \times 10^{-7}$ & $1.1 \times 10^{-8}$ & $3.1 \times 10^{-10}$ \\
$\mathrm{Fe}(\mathrm{CO})_{3}^{-}$ & $1.7 \times 10^{-7}$ & $5.5 \times 10^{-8}$ & $3.2 \times 10^{-8}$ \\
$\mathrm{Ni}(\mathrm{CO})_{3}^{-}$ & $2.0 \times 10^{-7}$ & $1.8 \times 10^{-8}$ & $3.1 \times 10^{-10}$ \\
$\mathrm{Mo}(\mathrm{CO})_{5}^{-}$ & $1.3 \times 10^{-7}$ & $2.0 \times 10^{-8}$ & $3.1 \times 10^{-10}$ \\
$\mathrm{~W}(\mathrm{CO})_{5}^{-}$ & $1.2 \times 10^{-7}$ & $2.0 \times 10^{-8}$ & $1.4 \times 10^{-11}$ \\
\hline \hline
\end{tabular}

${ }^{a}$ All rate constant units are $\mathrm{cm}^{3}$ molecule $\mathrm{m}^{-1} \mathrm{~s}^{-1}$.

${ }^{\mathrm{b}} k_{\text {app }}$ is the apparent electron attachment rate constant, measured in the limit of a high pressure of $\mathrm{CO}_{2}$.

${ }^{c} k_{m}$ is the electron attachment rate constant measured with the metal carbonyl alone.

${ }^{\mathrm{d}} \boldsymbol{k}_{\mathrm{CO}_{2}}$ is the apparent rate of electron thermalization by $\mathrm{CO}_{2}$.

process. This is not unreasonable since each dissociative electron capture process has a specific and distinct dependence on electron energy. The maximum cross section for each ion is different and occurs at different electron energies with varying peak widths. It is to be expected, therefore, that removal of electrons in a particular energy range by attachment processes will change the apparent rate of relaxation by $\mathrm{CO}_{2}$. If the cross section peaks sharply at low energies, then the apparent rate of relaxation by $\mathrm{CO}_{2}$ will be high. In the case of $\mathrm{CCl}_{4}$, which has a sharp dissociative attachment peak at thermal energies, ${ }^{14}$ the apparent rate of thermalization of electrons is as high as $5.8 \times 10^{-9}$ $\mathrm{cm}^{3}$ molecule $\mathrm{e}^{-1} \mathrm{~s}^{-1}$. Warman and Sauer $\mathrm{r}^{4}$ have noted that $\mathrm{CCl}_{4}$ possibly distorts the process of electron thermalization by $\mathrm{CO}_{2}$ due to rapid removal of electrons at the low end of the energy spectrum.

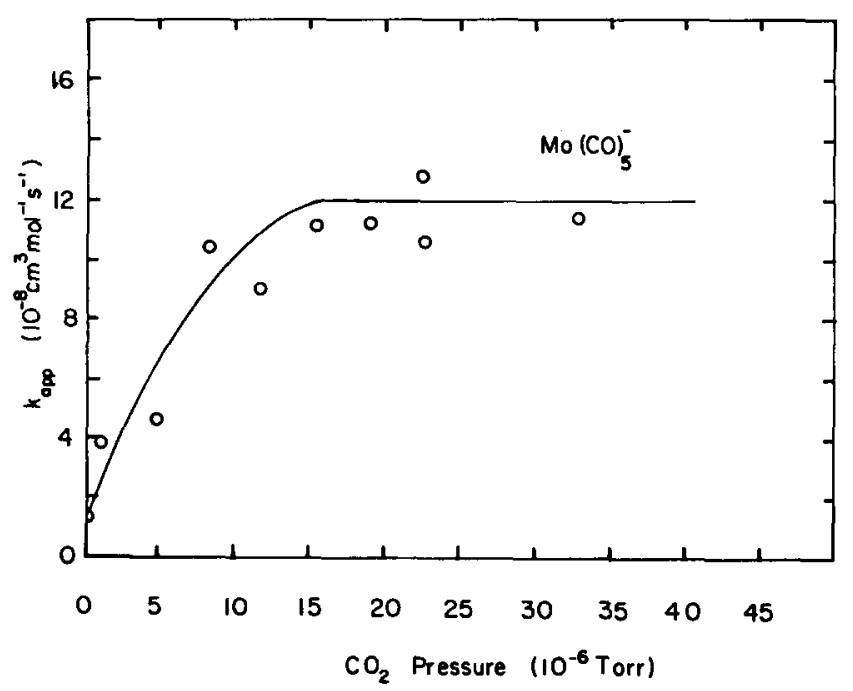

FIG. 11. Dissociative electron attachment rate constants as a function of $\mathrm{CO}_{2}$ pressure for $\mathrm{Mo}(\mathrm{CO})_{6}$.

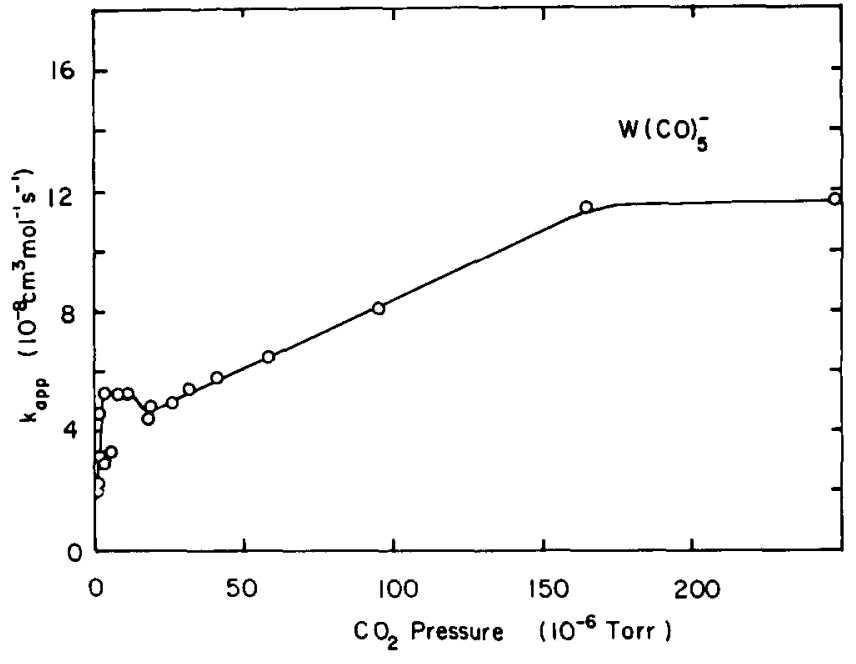

FIG. 12. Dissociative electron attachment rate constants as a function of $\mathrm{CO}_{2}$ pressure for $\mathrm{W}(\mathrm{CO})_{6}$.

As an example of the above discussion it can be seen that $\mathrm{Fe}(\mathrm{CO})_{4}^{-}$is formed with electrons in the range $0-3$ $\mathrm{eV}$ [Fig. 5(b)]. The apparent $\mathrm{CO}_{2}$ relaxation rate constant is $3.1 \times 10^{-10} \mathrm{~cm}^{3}$ molecule $\mathrm{e}^{-1} \mathrm{~s}^{-1}$. $\mathrm{Fe}(\mathrm{CO})_{3}^{-}$, however, is formed at higher energies and the apparent rate of thermalization of electrons by both $\mathrm{CO}_{2}$ and by $\mathrm{Fe}(\mathrm{CO})_{5}$ alone become almost comparable to the electron attachment rate observed at high $\mathrm{CO}_{2}$ pressures, i.e., very little or no thermalization is required to react a $0-1.3$ $\mathrm{eV}$ electron distribution with $\mathrm{Fe}(\mathrm{CO})_{5}$ in order to lose two CO ligands. This is in good agreement with obser vations ${ }^{10}$ that onset of $\mathrm{Fe}(\mathrm{CO})_{3}^{-}$formation occurs at zero electron energy but continues rising until a maximum is reached at $\sim 1.3 \mathrm{eV}$.

Rate constants for electron thermalization by $\mathrm{CO}_{2}$ obtained with some of the metal carbonyls correlate reasonably well with values calculated from Christophorou' ${ }^{3}$ studies of thermalization times as a function of mean electron energy. In fact, the values of $3 \times 10^{-10}$ $\mathrm{cm}^{3}$ molecule $\mathrm{e}^{-1} \mathrm{~s}^{-1}$ obtained when $\mathrm{Fe}(\mathrm{CO})_{4}^{-}, \mathrm{Mo}(\mathrm{CO})_{5}^{-}$, and $\mathrm{Ni}(\mathrm{CO})_{3}^{-}$were the monitoring species agree very well with the $3.8 \times 10^{-10} \mathrm{~cm}^{3}$ molecule $\mathrm{e}^{-1} \mathrm{~s}^{-1}$ calculated for an average electron energy of $0.7 \mathrm{eV}$. To better understand the distinct behavior indicated by $\mathrm{Cr}(\mathrm{CO})_{5}^{-}$and $\mathrm{W}(\mathrm{CO})_{5}^{-}$it would be valuable to determine cross sections for formation of these species as a function of electron energy. This would also be useful in explaining the un usual behavior observed in Fig. 12 for $k_{2 p p}$ as a function of $\mathrm{CO}_{2}$ pressure, which may be due to two peaks in the yield of $\mathrm{W}(\mathrm{CO})_{5}^{-}$as a function of electron energy.

\section{CONCLUSION}

With the exception of $\mathrm{V}(\mathrm{CO})_{6}$, the transition metal carbonyls all exhibit rate constants for dissociative electron capture which approach tha maximum ( $s$-wave) thermal attachment rate constant of $5 \times 10^{-7} \mathrm{~cm}^{3}$ molecule $^{-1} \mathrm{~s}^{-1}$ at $298 \mathrm{~K} .{ }^{15}$ In the case of $\mathrm{V}(\mathrm{CO})_{6}$, electron attachment should result in only minimum distortion in forming $\mathrm{V}(\mathrm{CO})_{6}^{-}$, which is known to be a stable species. The lower attachment rate measured for this species may reflect an increased probability of autodetachment 
relative to the remaining species, for which distortions "trap" the electron and lead eventually to loss of $\mathrm{CO}$.

This effect may also be responsible for the decrease in attachment rate observed in the series $\mathrm{Cr}(\mathrm{CO})_{6}$, $\mathrm{Mo}(\mathrm{CO})_{6}$, and $\mathrm{W}(\mathrm{CO})_{6}$.

The apparent rate of electron thermalization by $\mathrm{CO}_{2}$ depends on the specific dissociative electron capture process used to monitor the electron population. This is due to the rapid removal of electrons within particular energy ranges. Investigations of the formation of metal carbonyl ions as a function of electron energy would allow for a more detailed interpretation of the present experimental results.

${ }^{1}$ M. S. Foster and J. L. Beauchamp, Chem. Phys. Lett. 31, 482 (1975).

${ }^{2}$ R. L. Woodin, M. S. Foster, and J. L. Beauchamp, J. Chem. Phys. 72, 4223 (1980).

${ }^{3}$ L. G. Christophorou, K. S. Gant, and J. K. Baird, Chem. Phys. Lett. 30, 104 (1975).
${ }^{4} J$. M. Warman and M. C. Sauer, Jr. , J. Chem. Phys. 62, 1971 (1975).

${ }^{5} \mathrm{G}$. J. Schultz, in Principles of Laser Plasmas, edited by G. Bekefe (Wiley, New York, 1976).

${ }^{6}$ R. L. Sullivan and R. N. Kiser, J. Chem. Phys. 49, 1978 (1968).

${ }^{7}$ R. N. Kiser, R. L. Sullivan, and M. S. Lupin, Anal. Chem. 41,1958 (1969).

${ }^{8}$ R. E. Winters and R. N. Kiser, J. Chem. Phys. 44, 1964 (1966).

${ }^{9}$ R. L. Sullivan, M. S. Lupin, and R. W. Kiser, Chem. Commun. 1969,655 .

${ }^{10}$ R. N. Compton and J. A. D. Stockdale, Int. J. Mass Spectrom. Ion Phys. 22, 51 (1976).

${ }^{11} \mathrm{P}$. C. Engelking and W. C. Lineberger, J. Am. Chem. Soc. 101, 5569 (1979).

${ }^{12}$ T. B. McMahon and J. L. Beauchamp, Rev. Sci. Instrum. 43, 509 (1972).

${ }^{13}$ L. G. Christophorou and J. A. D. Stockdale, J. Chem. Phys. 48, 1956 (1968).

${ }^{14}$ R. P. Blaunstein and L. G. Christophorou, J. Chem. Phys. 49, 1526 (1968).

${ }^{15}$ L. G. Christophorou and R. P. Blaunstein, Chem. Phys. Lett. 12, 173 (1971). 